\title{
Gender inequalities in health among workers: the relation with family demands
}

\author{
L Artazcoz, C Borrell, J Benach
}

\begin{abstract}
Objectives-To analyse whether there are gender inequalities in health among male and female workers who are married or cohabiting and to assess whether there are gender differences in the relation between family demands and health. Additionally, for both objectives it will be examined whether these gender patterns are similar for manual and non-manual workers.
\end{abstract}

Design and setting-The data have been taken from the 1994 Catalonian Health Survey (CHS), a cross sectional survey based on a representative sample of the non-institutionalised population of Catalonia, a region in the north east of Spain that has about 6 million inhabitants. The dependent variables were four ill health indicators (self perceived health status, limiting longstanding illness, having at least one chronic condition and mental health) and two health related behaviours closely related to having time for oneself (no leisure time physical activity and sleeping six hours or less a day). Family demands were measured with three variables: household size, living with children under 15 years and living with adults older than 65 years. The analysis was separated for gender and social class (manual and non-manual workers) and additionally adjusted for age. Gender differences for all dependent and independent variables were first tested at the bivariate level using the $\chi^{2}$ test for categorical variables and the $t$ test for age. Secondly, multivariate logistic regression models were fitted.

Participants-Persons who were employed, married or cohabiting, aged 25 to 64 years (2148 men and 1185 women).

Results-A female excess for all the ill health indicators was found, while there were no gender differences in the health related behaviours analysed. Family demands had a greater impact on health and health related behaviours of female manual workers. In this group household size was positively related to four dependent variables. The adjusted odds ratios (ORs) to living in family units of more than four persons versus living only with the spouse were $2.74(95 \% \mathrm{CI}=1.22,6.17)$ for poor self perceived health status, 3.16 $(95 \% \mathrm{CI}=0.98,10.15)$ for limiting long standing illness, $3.28(95 \% \mathrm{CI}=1.45,7.44)$ for having at least one chronic condition, and $2.60(95 \% \mathrm{CI}=1.12,6.00)$ for sleeping six hours or less a day. Among female manual workers living with children under 15 years was positively associated with no leisure time physical activity (adjusted $\mathrm{OR}=2.37$; 95\% $\mathrm{CI}=1.43,3.92$ ) and with sleeping six hours or less a day (adjusted OR=1.91; 95\% $C I=1.13,3.32$ ). Living with adults older than 65 years had an unexpected negative relation with poor self perceived health status (adjusted $\mathrm{OR}=0.33 ; 95 \% \mathrm{CI}=0.16,0.66$ ), and with chronic conditions (adjusted $\mathrm{OR}=\mathbf{0 . 4 5}$; $95 \% \mathrm{CI}=0.24,0.87$ ) in female manual workers. Among male manual workers living with children under 15 years was positively associated with longstanding limiting illness (adjusted $O R=2.44$; 95\%CI=1.36, 4.38).

Conclusion-When gender differences in health are analysed, both the paid and the non-paid work should be considered as well as the interaction between these two dimensions, gender and social class. In Catalonia, as probably in Spain and in other countries, private changes such as sharing domestic responsibilities, as well as active public policies for facilitating family care are needed in order to reduce gender health inequalities attributable to the unequal distribution of family demands.

(F Epidemiol Community Health 2001;55:639-647)

In recent years some epidemiological studies have suggested that the common assumption of women's greater morbidity than men is not as generalisable as it seemed. Some studies have not found gender health differences, ${ }^{1-3}$ whereas in a study in Britain, Macintyre et $a l^{4}$ observed that the direction and magnitude of gender differences in health varied according to the particular symptom or condition in question, and according to the phase of life cycle. Additionally, some comparative studies have found different magnitude of gender health inequalities across countries. $^{56}$

Given that gender differences in health are associated with the social positions of men and women in contemporary society, ${ }^{7}$ inconsistencies in the pattern of gender health inequalities across countries or age strata may be related to different gender allocations determined by cultural attitudes towards gender, social class, social policy models or labour market patterns. Furthermore, differences in gender role attitudes across cultural settings can shape the meaning of each social position, the experience and reporting of different ill health conditions and the relation between social positions and health. 
A large number of studies have examined men's and women's health from different social perspectives. Research on men's health has been dominated by a structural framework focusing on occupational class differentials in morbidity and mortality, whereas women's health has been studied primarily using a role framework, emphasising women's roles as housewives and mothers with paid employment seen as an additional role. ${ }^{8}$ The dominance of the role framework in studying women's ill health contrasts with the paucity of attention to family roles and their influence in health in men, as well as to the gender health inequalities emerging from the unequal distribution of family demands. ${ }^{9} 10$

Despite the dramatic increase of women in the labour market in recent decades, there has been no significant change in the distribution of domestic work, even when both partners are working. ${ }^{71}$ The sexual division of labour dictates that even when women enter employment, they will typically still have the main responsibility for childcare and housework. Women do not have yet the power to oblige men to undertake an equal share of domestic labour and childcare, no matter how high the status of their employment is. ${ }^{12}$ These factors are likely to play an important part in explaining gender inequalities in health.

The influence of multiple roles as an employee, a spouse and a mother on women's health has been examined, but the results are not consistent. The contradictory findings in the role literature may be attributable to the insufficient characterisation of each role. In some studies multiple roles implies having more than one principal role (thus number of roles is the focus); in others, it means combining job and family responsibilities (thus, type of roles). ${ }^{8}$ However, the relation between multiple roles and health not only depends on the number or the type of roles occupied, but also on the nature of the particular roles - that is, the exposures related to the job differ by occupational status, or those associated with marital or parental status depend to a great extent on the family demands associated to these roles. Moreover, the effect of family demands on health may be different for different employment status or even for the same employment status there may be an interaction with occupational social class.

In Spain a handful of studies on health inequalities have been carried out. Most of them have focused on the relation between health and occupational social class or the level of education, ${ }^{13-15}$ but little is known about gender health inequalities, ${ }^{16}{ }^{17}$ particularly in relation to domestic work. There are a number of reasons why Spain occupies a theoretically interesting role in such research. On the one hand, the participation of Spanish women in the labour market is lower than in other countries of the European Union (EU) (in 1998 the women's activity rate was $37 \%$, whereas the mean of the EU was $46 \%$ and there were countries such as Denmark where the proportion was near $60 \%$ ) and part time work among women is one of the lowest in the EU (in 1998 only $17 \%$ of female workers were in part time jobs, while the mean in the EU was $33 \%) .{ }^{18}$ On the other hand, social services for families are underdeveloped, there are minimal publicly funded day care places and involvement of men in domestic work is very low. ${ }^{19}$

The objectives of this study are: firstly, to determine whether there are gender inequalities in health among male and female workers who are married or cohabiting; secondly, to assess whether there are gender differences in the relation between family demands and health. Additionally, for both objectives we will examine whether these gender patterns are the same for manual and non-manual workers.

\section{Methods}

DATA

The data have been taken from the 1994 Catalonian Health Survey (CHS), a cross sectional survey based on a representative sample of the non-institutionalised population of Catalonia, a region in the north east of Spain which has about 6 million inhabitants. The survey included self reported information on morbidity, health status, health related behaviours and use of health care services as well as sociodemographic data. Fifteen thousand subjects were randomly selected using a multiple stage random sampling strategy. For each of the eight health regions of Catalonia, the first sampling stage consisted of selecting municipalities (or municipal districts in the case of the Barcelona City health region) according to their population size (eight strata). In each of these strata, cluster random sampling was used to select people by using proportional probabilities according to the weight of the municipality (or district). Trained interviewers administered the questionnaires at home in a face to face interview from January to December 1994 to avoid a potential seasonal bias. Only $5.4 \%$ of subjects were substituted because of refusal or absence of those initially selected. Half of the total sample was aged 25-64 years. In this age stratum $76 \%$ of men and $41 \%$ of women were employed and $80 \%$ were married or cohabiting. The population analysed in this study were the 2148 men and 1185 women who were employed, married or cohabiting, aged 25 to 64 years. Full details of the survey are reported elsewhere. ${ }^{20}$

MEASUREMENT OF ILL HEALTH

Four health indicators were included in the analysis:

- Self perceived health status, which was elicited by asking the respondents to describe their general health as "excellent", "very good", "good", "fair" or "poor". The variable was dichotomised by combining the categories "fair" and "poor" to indicate perceived health as below good. Self perceived health is a broad indicator of health related well being ${ }^{21}$ and has also proved to be a good predictor of mortality, even better than the medical diagnostic. ${ }^{22}$

- Limiting longstanding illness (LLI) was asked with the question "During the last 12 months have you had any trouble or 
difficulty for gainful employment, housework, schooling, studying, because of a chronic health problem (that has lasted or it is expected to last three or more months)?”. LLI is a functional measure of ill health, directing attention to the consequences of illness-that is, whether reported illness restricts daily activities or not. It represents the consequences of health status for what the individual perceives as his or her normal activities, providing a self assessment of the effect of any chronic ill health on daily life.

- Chronic conditions: suffering from none versus suffering from at least one chronic condition of the 23 listed chronic conditions.

- Mental health was measured with the 12 item version of the General Health Questionnaire (12-GHQ). ${ }^{23}$ This is a screening instrument widely used to detect minor psychiatric morbidity. The 12 item version has been recommended for use in employment studies and has been shown to be responsive to both gender differences and differences in occupational status. ${ }^{24}$ Here we used a two point scoring method, rating a problem as absent (0) or present (1). Responses were summed and a score higher than 2 was used to indicate the presence of psychiatric morbidity.

Additionally, two health related behaviours, leisure time physical activity and hours of sleeping, closely related to constraints of time (among other reasons) were analysed. These concepts were operationalised as follows:

- Leisure time physical activity: physical activity in the past 15 days was asked with three questions about the number of occasions on which the subject had performed various listed sports, for at least 20 minutes, of slight intensity, moderate intensity and of high intensity. A dichotomous variable was created, comparing no physical activity versus slight, moderate or high intensity of sport activities.

- Daily number of hours slept: lowest quartile versus the rest. The cut off point, six hours, was the same for men and women.

MEASUREMENT OF FAMILY DEMANDS

Family demands were measured with three variables:

(1) Household size, with four categories, "Two persons", "Three persons", "Four persons", and "More than four persons".

(2) Living with children under 15 years.

(3) Living with people older than 65 years.

DATA ANALYSIS

The analysis was stratified for gender and occupational social class (manual and nonmanual workers). Social class, assigned according to the respondent's current occupation, was measured with a widely used Spanish adaptation of the British classification. ${ }^{25}$ Class I includes managerial and senior technical staff and freelance professionals; class II intermediate occupations and managers in commerce; class III, skilled non manual workers; class IV, skilled (IVa) and partly skilled (IVb) manual workers; and class V, unskilled manual workers.
To test whether gender patterns were the same for manual and non-manual workers, the six original classes were collapsed into these two categories: non-manual workers (classes I, II and III) and manual workers (classes IVA, IVB and $\mathrm{V}$ ). The analysis was adjusted for age (in years).

The analysis was performed in three steps. Firstly, differences between men and women for all the dependent and independent variables were tested by using the $\chi^{2}$ test for categorical variables and the $t$ test for age. Secondly, multiple logistic regression models were fitted for each dependent variable to test whether or not there were gender differences. Gender was entered as the main independent variable and the models were additionally adjusted for age and secondly for both age and family demands. Finally multiple logistic regression models separated for gender and occupational class were fitted for each dependent variable in order to analyse the different gender patterns in the relation between family demands and health and health related behaviours, after adjusting for age. The results of the models are presented as adjusted odds ratios (OR) with their 95\% Wald confidence intervals (CI). The reference categories for all the independent variables were those hypothesised a priori as of lower risk. Goodness of fit was obtained using the Hosmer Lemeshow test. ${ }^{26}$ All analysis included the weights derived from the complex sample design. ${ }^{27}$

\section{Results}

COMPARISONS BETWEEN MEN AND WOMEN

Women were younger and showed slightly lower percentages of manual class workers than men $(46 \% v 51 \%)$. The prevalence of chronic conditions and poor mental health was significantly higher among women in both social classes, whereas differences were not statistically significant for poor self perceived health status and LLI. There were no gender differences in the health related behaviours. Family demands variables were similar for both gender and classes except for living with children under 15 years, which was more frequent among non-manual female workers. Twenty one per cent of the sample lived in households with more than four members and $11 \%$ lived with persons older than 65 years (table 1).

After adjusting for age, gender differences in ill health were statistically significant for the four health indicators analysed and ORs almost did not change when logistic regression models were additionally adjusted for family demands. Among manual workers the magnitude of gender differences in mental health was much higher than among non-manual workers (adjusted $\mathrm{OR}=2.21 ; 95 \% \mathrm{CI}=1.68,2.90$ and $\mathrm{OR}=1.39 ; 95 \% \mathrm{CI}=1.04,1.86$ respectively). As in the crude analysis, there were no gender differences in leisure time physical activity or in time spent sleeping (table 2). 
Table 1 General characteristics of the study sample (in percentages). Catalonia Health Survey, 1994

\begin{tabular}{|c|c|c|c|c|c|c|}
\hline \multirow[b]{2}{*}{ Health outcomes } & \multicolumn{3}{|c|}{ Non-manual } & \multicolumn{3}{|l|}{ Manual } \\
\hline & $\begin{array}{l}\text { Men } \\
(n=1071)\end{array}$ & $\begin{array}{l}\text { Women } \\
(n=645)\end{array}$ & $p$ & $\begin{array}{l}\text { Men } \\
(n=1077)\end{array}$ & $\begin{array}{l}\text { Women } \\
(n=540)\end{array}$ & $p$ \\
\hline \multicolumn{7}{|l|}{ Self perceived health status } \\
\hline Excellent & 8.9 & 6.7 & 0.12 & 3.7 & 4.5 & 0.06 \\
\hline Very good & 14.0 & 15.3 & & 11.6 & 10.9 & \\
\hline Good & 65.5 & 63.7 & & 64.1 & 58.0 & \\
\hline Fair & 10.8 & 12.6 & & 19.1 & 24.6 & \\
\hline Poor & 0.7 & 1.7 & & 1.4 & 2.1 & \\
\hline Limiting longstanding illness & 6.9 & 8.6 & 0.20 & 9.5 & 11.9 & 0.14 \\
\hline At least one chronic condition & 51.1 & 59.4 & 0.0008 & 56.6 & 66.5 & 0.0001 \\
\hline GHQ score $>2$ & 12.1 & 15.7 & 0.03 & 12.7 & 23.6 & $<0.0001$ \\
\hline \multicolumn{7}{|l|}{ Health related behaviours } \\
\hline No leisure time physical activity & 28.3 & 26.8 & 0.51 & 34.2 & 35.3 & 0.66 \\
\hline Daily number of hours slept $\leqslant 6$ & 29.3 & 28.5 & 0.73 & 26.5 & 30.1 & 0.14 \\
\hline \multicolumn{7}{|l|}{$\begin{array}{l}\text { Family demands } \\
\text { Household size }\end{array}$} \\
\hline Two & 13.9 & 14.8 & 0.05 & 10.0 & 11.7 & 0.10 \\
\hline Three & 24.7 & 30.1 & & 26.4 & 31.1 & \\
\hline Four & 41.2 & 35.6 & & 41.4 & 37.6 & \\
\hline$>$ Four & 20.2 & 19.4 & & 22.2 & 19.7 & \\
\hline Living with children under 15 & 50.1 & 60.8 & $<0.0001$ & 54.0 & 54.0 & 1.00 \\
\hline Living with persons older than 65 & 11.4 & 9.3 & 0.18 & 12.1 & 10.9 & 0.46 \\
\hline Age (mean and SD) & $44.1(9.4)$ & $40.2(8.9)$ & $<0.0001$ & $44.7(9.8)$ & $41.6(9.4)$ & $<0.0001$ \\
\hline
\end{tabular}

RELATION BETWEEN FAMILY DEMANDS AND

HEALTH OUTCOMES

Factors associated with ill health differed by gender and social class. Among non-manual workers, for both men and women, family demands were not associated with any health indicator. Nevertheless, among manual men, living with children under 15 years (adjusted $\mathrm{OR}=2.44 ; 95 \% \mathrm{CI}=1.36,4.38)$ or with persons older than 65 years (adjusted $\mathrm{OR}=1.64$; $95 \% \mathrm{CI}=0.90,2.98)$ was positively associated with LLI (table 3).

Household size had a greater impact in female manual workers' health (table 4). Thus, a significant adverse effect on three of the ill health indicators - self perceived health status, LLI and chronic conditions-was observed. Interestingly there was a consistent gradient. In this group the adjusted ORs associated to living in household units of more than four persons as compared with the referent category were 2.74 $(95 \% \mathrm{CI}=1.22,6.17)$ for self perceived health status, $3.16(95 \% \mathrm{CI}=0.98,10.15)$ for LLI and $3.28(95 \% \mathrm{CI}=1.45,7.44)$ for having at least one chronic condition. Neither in men nor in women was household size associated to mental health.

Among women, living with children under 15 years was not associated with any health indicator but, unexpectedly, among female manual workers living with persons older than 65 years showed a statistically significant negative association with self perceived health status (adjusted $\mathrm{OR}=0.33 ; 95 \% \mathrm{CI}=0.16,0.66$ ) and having at least one chronic condition (adjusted $\mathrm{OR}=0.45 ; 95 \% \mathrm{CI}=0.24,0.87)$.

RELATION OF FAMILY DEMANDS WITH LEISURE TIME PHYSICAL ACTIVITY AND TIME SPENT IN SLEEPING

Among men, family demands were not associated with health related behaviours (table 5). However, for women, family demands showed a positive association (table 6). Among manual female workers, no leisure time physical activity was more frequent among those living with children under 15 years (adjusted $\mathrm{OR}=2.37 ; 95 \% \mathrm{CI}=1.43,3.92)$ and sleeping $\mathrm{six}$

Table 2 Odds ratios (OR) and 95\% confidence intervals (CI) comparing health outcomes and health related behaviours of women to men

\begin{tabular}{|c|c|c|c|c|}
\hline & \multicolumn{2}{|l|}{ Non-manual } & \multicolumn{2}{|l|}{ Manual } \\
\hline & $\begin{array}{l}\text { Men } \\
\text { (referent category) }\end{array}$ & OR $(95 \% C I)$ & $\begin{array}{l}\text { Men } \\
\text { (referent category) }\end{array}$ & OR $(95 \% C I)$ \\
\hline \multicolumn{5}{|l|}{ Poor self perceived health status } \\
\hline Adjusted for age & 1 & $1.54(1.14,2.08)$ & 1 & $1.69(1.31,2.18)$ \\
\hline Adjusted for age and family demands & 1 & $1.55(1.15,2.10)$ & 1 & $1.80(1.39,2.33)$ \\
\hline \multicolumn{5}{|l|}{ Limiting longstanding illness } \\
\hline Adjusted for age & 1 & $1.45(1.00,2.11)$ & 1 & $1.39(1.00,1.95)$ \\
\hline Adjusted for age and family demands & 1 & $1.45(1.00,2.12)$ & 1 & $1.45(1.03,2.04)$ \\
\hline \multicolumn{5}{|l|}{ At least one chronic condition } \\
\hline Adjusted for age & 1 & $1.68(1.37,2.07)$ & 1 & $1.79(1.43,2.24)$ \\
\hline Adjusted for age and family demands & 1 & $1.70(1.38,2.10)$ & 1 & $1.80(1.44,2.26)$ \\
\hline \multicolumn{5}{|l|}{$12-G H Q>2$} \\
\hline Adjusted for age & 1 & $1.39(1.04,1.85)$ & 1 & $2.17(1.65,2.84)$ \\
\hline Adjusted for age and family demands & 1 & $1.39(1.04,1.86)$ & 1 & $2.21(1.68,2.90)$ \\
\hline \multicolumn{5}{|l|}{ No leisure time physical activity } \\
\hline Adjusted for age & 1 & $0.96(0.77,1.20)$ & 1 & $1.06(0.85,1.32)$ \\
\hline Adjusted for age and family demands & 1 & $0.94(0.75,1.18)$ & 1 & $1.08(0.86,1.34)$ \\
\hline \multicolumn{5}{|l|}{ Sleeping $\leqslant 6$ hours a day } \\
\hline Adjusted for age & 1 & $0.96(0.77,1.19)$ & 1 & $1.22(0.97,1.54)$ \\
\hline Adjusted for age and family demands & 1 & $0.95(0.77,1.19)$ & 1 & $1.24(0.98,1.56)$ \\
\hline
\end{tabular}


Table 3 Multivariate odds ratios (OR) and 95\% confidence intervals (CI) for the associations between health outcomes and the independent variables in men. Catalonia Health Survey, 1994

\begin{tabular}{|c|c|c|c|c|c|c|c|c|}
\hline & \multicolumn{2}{|c|}{ Poor self perceived health status } & \multicolumn{2}{|c|}{ Limiting longstanding illness } & \multicolumn{2}{|c|}{ At least one chronic condition } & \multicolumn{2}{|l|}{$12-G H Q>2$} \\
\hline & Non-manual & Manual & Non-manual & Manual & Non-manual & Manual & Non-manual & Manual \\
\hline \multicolumn{9}{|c|}{ Household size } \\
\hline Two & 1 & 1 & 1 & 1 & 1 & 1 & 1 & 1 \\
\hline Three & $1.13(0.54,2.37)$ & $0.91(0.49,1.69)$ & $1.06(0.40,2.79)$ & $0.78(0.34,1.81)$ & $0.65(0.41,1.04)$ & $1.23(0.74,2.06)$ & $0.70(0.35,1.39)$ & $1.03(0.49,2.17)$ \\
\hline Four & $1.47(0.74,2.91)$ & $1.10(0.60,2.00)$ & $1.39(0.56,3.45)$ & $0.56(0.24,1.29)$ & $0.84(0.54,1.32)$ & $1.19(0.72,1.97)$ & $0.93(0.49,1.76)$ & $0.90(0.43,1.90)$ \\
\hline$>$ Four & $1.63(0.74,3.59)$ & $0.91(0.46,1.77)$ & $1.08(0.37,3.11)$ & $0.61(0.24,1.54)$ & $0.86(0.50,1.48)$ & $0.94(0.53,1.67)$ & $0.70(0.32,1.55)$ & $0.92(0.40,2.11)$ \\
\hline \multicolumn{9}{|c|}{ Living with children below 15} \\
\hline No & 1 & 1 & 1 & 1 & 1 & 1 & 1 & 1 \\
\hline Yes & $0.77(0.46,1.28)$ & $1.37(0.91,2.07)$ & $1.23(0.64,2.38)$ & $2.44(1.36,4.38)$ & $1.10(0.78,1.55)$ & $1.15(0.82,1.62)$ & $1.02(0.61,1.70)$ & $1.47(0.89,2.43)$ \\
\hline \multicolumn{9}{|c|}{ Living with persons older than 65} \\
\hline No & 1 & 1 & 1 & 1 & 1 & 1 & 1 & 1 \\
\hline Yes & $0.88(0.48,1.62)$ & $0.77(0.47,1.26)$ & $1.36(0.65,2.85)$ & $1.64(0.90,2.98)$ & $1.41(0.91,2.16)$ & $1.18(0.78,1.80)$ & $0.85(0.43,1.68)$ & $0.81(0.43,1.50)$ \\
\hline
\end{tabular}

Odds ratios are also adjusted for age.

Table 4 Multivariate odds ratios (OR) and 95\% confidence intervals (CI) for the associations between health outcomes and the independent variables in women. Catalonia Health Survey, 1994

\begin{tabular}{|c|c|c|c|c|c|c|c|c|}
\hline & \multicolumn{2}{|c|}{ Poor self perceived health status } & \multicolumn{2}{|c|}{ Limiting longstanding illness } & \multicolumn{2}{|c|}{ At least one chronic condition } & \multicolumn{2}{|l|}{$12-G H Q>2$} \\
\hline & Non-manual & Manual & Non-manual & Manual & Non-manual & Manual & Non-manual & Manual \\
\hline \multicolumn{9}{|c|}{ Household size } \\
\hline Two & 1 & 1 & 1 & 1 & 1 & 1 & 1 & 1 \\
\hline Three & $1.64(0.71,3.74)$ & $0.98(0.44,2.15)$ & $0.77(0.27,2.20)$ & $1.71(0.54,5.39)$ & $0.80(0.43,1.52)$ & $1.15(0.58,2.29)$ & $1.14(0.51,2.58)$ & $1.13(0.53,2.41)$ \\
\hline Four & $1.36(0.60,3.08)$ & $1.80(0.83,3.89)$ & $0.81(0.30,2.23)$ & $2.40(0.78,7.38)$ & $1.08(0.57,2.05)$ & $1.56(0.78,3.15)$ & $0.94(0.41,2.13)$ & $1.22(0.57,2.61)$ \\
\hline$>$ Four & $2.16(0.90,5.21)$ & $2.74(1.22,6.17)$ & $1.69(0.59,4.81)$ & $3.16(0.98,10.15)$ & $0.91(0.44,1.90)$ & $3.28(1.45,7.44)$ & $1.64(0.68,3.97)$ & $1.35(0.59,3.06)$ \\
\hline \multicolumn{9}{|c|}{ Living with children below 15} \\
\hline No & 1 & 1 & 1 & 1 & 1 & 1 & 1 & 1 \\
\hline Yes & $0.66(0.37,1.20)$ & $1.05(0.62,1.78)$ & $1.22(0.58,2.60)$ & $0.80(0.40,1.58)$ & $1.02(0.63,1.64)$ & $0.83(0.49,1.39)$ & $1.03(0.57,1.87)$ & $0.95(0.56,1.62)$ \\
\hline \multicolumn{9}{|c|}{ Living with persons older than 65} \\
\hline No & 1 & 1 & 1 & 1 & 1 & 1 & 1 & 1 \\
\hline Yes & $1.15(0.57,2.32)$ & $0.33(0.16,0.66)$ & $0.58(0.22,1.55)$ & $0.63(0.26,1.55)$ & $1.01(0.53,1.91)$ & $0.45(0.24,0.87)$ & $1.08(0.52,2.24)$ & $1.05(0.54,2.04)$ \\
\hline
\end{tabular}

Odds ratios are also adjusted for age.

Table 5 Multivariate odds ratios (OR) and 95\% confidence intervals (CI) for the associations between health related behaviours and the independent variables in men. Catalonia Health Survey, 1994

\begin{tabular}{|c|c|c|c|c|}
\hline & \multicolumn{2}{|c|}{ No leisure time physical activity } & \multicolumn{2}{|l|}{ Daily hours slept $\leqslant 6$} \\
\hline & Non-manual & Manual & Non-manual & Manual \\
\hline \multicolumn{5}{|c|}{ Household size } \\
\hline Two & 1 & 1 & 1 & 1 \\
\hline Three & $1.66(0.96,2.88)$ & $1.14(0.69,1.90)$ & $1.15(0.69,1.93)$ & $1.24(0.70,2.20)$ \\
\hline Four & $1.39(0.81,2.39)$ & $0.83(0.50,1.38)$ & $1.39(0.85,2.28)$ & $1.56(0.89,2.73)$ \\
\hline$>$ Four & $1.78(0.96,3.29)$ & $1.31(0.74,2.32)$ & $1.10(0.61,1.99)$ & $1.61(0.86,3.03)$ \\
\hline \multicolumn{5}{|c|}{ Living with children below 15} \\
\hline No & 1 & 1 & 1 & 1 \\
\hline Yes & $1.32(0.90,1.93)$ & $0.98(0.69,1.39)$ & $0.97(0.67,1.41)$ & $0.78(0.53,1.13)$ \\
\hline \multicolumn{5}{|c|}{ Living with persons older than 65} \\
\hline No & 1 & 1 & 1 & 1 \\
\hline Yes & $1.53(0.99,2.37)$ & $0.79(0.52,1.22)$ & $0.99(0.62,1.57)$ & $0.89(0.57,1.41)$ \\
\hline
\end{tabular}

Odds ratios are also adjusted for age.

Table 6 Multivariate odds ratios (OR) and 95\% confidence intervals (CI) for the associations between health related behaviours and the independent variables in women. Catalonia Health Survey, 1994

\begin{tabular}{|c|c|c|c|c|}
\hline & \multicolumn{2}{|c|}{ No leisure time physical activity } & \multicolumn{2}{|l|}{ Daily hours slept $\leqslant 6$} \\
\hline & Non-manual & Manual & Non-manual & Manual \\
\hline \multicolumn{5}{|c|}{ Household size } \\
\hline Two & 1 & 1 & 1 & 1 \\
\hline Three & $1.12(0.57,2.22)$ & $0.89(0.44,1.78)$ & $0.98(0.50,1.92)$ & $1.82(0.82,4.03)$ \\
\hline Four & $1.14(0.58,2.24)$ & $0.71(0.35,1.45)$ & $1.27(0.65,2.46)$ & $1.40(0.63,3.14)$ \\
\hline$>$ Four & $2.12(1.01,4.46)$ & $1.32(0.63,2.79)$ & $1.71(0.81,3.59)$ & $2.60(1.12,6.00)$ \\
\hline \multicolumn{5}{|c|}{ Living with children below 15} \\
\hline No & 1 & 1 & 1 & 1 \\
\hline Yes & $1.01(0.62,1.66)$ & $2.37(1.43,3.92)$ & $1.02(0.62,1.66)$ & $1.91(1.13,3.22)$ \\
\hline \multicolumn{5}{|c|}{ Living with persons older than 65} \\
\hline No & 1 & 1 & 1 & 1 \\
\hline Yes & $0.99(0.53,1.85)$ & $1.06(0.58,1.95)$ & $0.82(0.43,1.57)$ & $0.67(0.35,1.27)$ \\
\hline
\end{tabular}

Odds ratios are also adjusted for age. hours or less a day was related to household size (the adjusted OR for living in household units of more than four persons was 2.60; $95 \% \mathrm{CI}=1.12,6.00)$ and to living with children under 15 years (adjusted $\mathrm{OR}=1.91$; $95 \% \mathrm{CI}=1.13$, 3.22). Household size was also positively associated with no leisure time physical activity among female non-manual workers.

\section{Discussion}

COMPARISONS BETWEEN MEN AND WOMEN

As in many studies, morbidity, as measured with four health indicators, was higher among women, ${ }^{5-9}{ }^{28-30}$ in both manual and non-manual social classes. Moreover, gender health differences were not accounted for by differences in age or family demands. Some studies have not found gender differences in health, ${ }^{23}$ whereas others have found a female excess only for some health indicators. ${ }^{41}$ In the present population there were no gender differences in reported leisure time physical activity or in sleeping six hours or less. These findings are consistent with the results of Bird et $a l^{32}$ who did not find differences between men and women in the time spent in active leisure time physical activity and in sleeping. However, others have found that men are more likely to be involved in sport activities than women. ${ }^{30} 33$

These differences in the gender pattern of health and health related behaviours between studies might be accounted for by differences in the cultural settings being analysed or by the specific characteristics of the samples. There is 
a high heterogeneity among studies in the populations analysed. Most of them have studied general populations with no role restrictions $^{31}$; others have restricted the populations by age, socioeconomic status or occupation. There is also a high heterogeneity in the health outcomes analysed and, although it has been reported that gender differences in health vary according to the symptom or health condition considered, many studies have focused on only one health indicator. ${ }^{34}$ This lack of a systematic approach makes comparisons between studies difficult, and emphasises the need for increasing efforts directed at the development of theoretical models that are sensitive to social structural dimensions of gender relations if we want to fully understand gender patterns of health and illness. ${ }^{34} 35$

RELATION BETWEEN FAMILY DEMANDS AND HEALTH OUTCOMES IN MEN AND WOMEN

Family demands had a greater impact on health of female manual workers. Household size had a consistent positive relation with three of the four health indicators. Moreover a consistent gradient was found. Although household size has seldom been used as a measure of family demands, it seems to be a good indicator of total domestic workload for married women, more sensitive, in this study, to women's health than living with children under 15 years. For example, Walters ${ }^{36}$ observed that stress was more frequent among women in larger households.

Obviously, family demands depend not only on household size, but also on other variables such as the age of children and the number of them in each age strata living at home, ${ }^{8}$ but these data were not collected in the CHS. Most studies have generally equated domestic responsibilities with children. The evidence about the effect of parenthood on health overall shows that among women children at home decrease psychological well being or have no impact at all. ${ }^{37}$ Children may improve well being in favourable circumstances including sufficient family income, mother's paid employment, available and affordable child care services, and support from husband or other relatives in the household. ${ }^{38}$

Among manual female workers living with adults older than 65 years showed an unexpected negative association with three out of four ill health indicators (although the association was not statistically significant for LLI). Walters ${ }^{36}$ found that stress and anxiety were more frequent among women who reported caring for an elderly or sick relative. In a study of nurses, caring for a dependent adult was a risk factor for women but not for men. ${ }^{29}$ Bartley et $a l^{11}$ included cohabiting with adults older than 75 years in a combined measure of domestic conditions considering them a priori as a source of workload. However, they pointed out that it was impossible to establish whether co-resident older adults in the household were themselves either receiving care or, as in many cases, providing it. This may be the case in the present study. Nowadays people older than 65 years have few limitations in their daily
KEY POINTS

- Women showed a higher prevalence of poor self perceived health status, limiting longstanding illness, having at least one chronic condition and poor mental health both among manual and non-manual workers.

- No gender differences were found for reported leisure time physical activity and sleeping six hours or less a day.

- Among female manual workers, family demands were associated with all health outcomes except poor mental health.

- Among female manual workers, living with persons older than 65 years had a negative association with poor self perceived health status and chronic conditions.

- Among male manual workers, living with children under 15 years had a positive association with longstanding limiting illness.

activities, as compared with some years ago. ${ }^{39}$ In addition, those living with female workers might have even a better health status than others of the same age, because otherwise women usually have to leave the labour market to take care of them or, if they have enough economic resources, send them to geriatric residences. Thus, it seems probable that the negative association between living with older adults and health among female manual workers may be mediated by the emotional and/or instrumental support they provide (for example they can look after the children at home). Although it is likely that the oldest people had a poor health status, and they might be more a source of work demands than of support, unfortunately additional information on age was not available. Given that the population of elderly is growing rapidly, it would be worthwhile to include more detailed information about the age of people older than 65 living at home in future health surveys.

Recent studies have pointed out the importance of working part time or full time for women's health. Bartley et $a l^{40}$ observed that while health in women without children was better in full time paid workers as compared with those without paid employment, a tendency for an opposite relation was found for women with children. Full time working mothers had a significantly increased risk for poor health compared with mothers with part time or no paid employment. In another study women with full time and part time paid work were more likely to experience lower levels of physical and psychological symptoms than housewives, but part time work seemed to be more advantageous. ${ }^{11}$ Although in this study this variable was not available, in 1994 only $15 \%$ of female Catalonian workers were in part time jobs. ${ }^{41}$ This means that most of them had a full time job and they probably had also to assume the majority of domestic tasks.

Family demands were related to men's health only among manual workers in the case 
of LLI. Living with children under 15 years and with persons older than 65 years were positively associated to LLI (although $\mathrm{p}=0.1$ for living with elderly). More than half of the causes of LLI were musculoskeletal, mainly back pain related. Men's back pain has been associated with young children ${ }^{42}$ and we may speculate that the association between men's health and living with young children or people older than 65 years could be explained by a division of domestic workload that would assign activities related to the use of physical effort for moving children or disabled old persons to men. To confirm this hypothesis will require further research.

Reporting no leisure time physical activity was positively related to living with children under 15 years among female manual workers. A lack of time is the most commonly cited barrier for participation in physical activity ${ }^{43}$ and caring for children might mean, not only a lack of time, but also a constraint to autonomy and consequent difficulties for leisure time physical activities among working class married women. Household size and living with children under 15 years were also associated with sleeping six hours or less a day among female manual workers. These results suggest that working class women "finance" the double burden of job and family demands with reductions in their personal time.

One of the issues that has been neglected in the research on gender differences in health is whether they are influenced by social class. ${ }^{35}$ In this study we have provided some evidence that, although there is a female excess of morbidity both among manual and non-manual workers, the relation between family demands and health does not only depend on gender but also on social class. Family demands are mainly associated with female manual workers' health. This finding can be related both to the interaction between family demands and the psychosocial job characteristics or the material conditions where domestic work is carried out. Lennon et $a l^{44}$ reported that the degree of control at work (higher among nonmanual workers) moderates the effects of demands in the family. On the other hand, women of non-manual social class have higher resources for facing domestic work. Cleary et $a l^{45}$ found a positive relation between the number of children in the household and depression in women with paid employment but this relation was insignificant after controlling for family income. High income enables paid help with domestic tasks and childcare to relieve working women of some of the overload. Among female manual workers elderly people living at home could assume this role of support for doing domestic tasks. Another interesting aspect to be considered could be how the social class of the spouse influences gender patterns on health but unfortunately this information was not collected in the CHS.

In conclusion, as Emslie et $a l^{11}$ have noted, many previous studies on gender and health have been based on general population samples but given the strongly gendered nature of contemporary society, comparisons between men and women may be confounded with comparisons between other axes of social differentiation such as employment and domestic roles. Moreover, the effect of family demands may depend on employment and marital status making it necessary to consider multiple interaction terms that could make interpretation of results difficult. These limitations have been reduced in this study with the restriction of the population analysed to those employed and married or cohabiting.

In summary, we have found a female excess in the four ill health indicators analysed-self perceived health status, LLI, having at least one chronic condition and mental health-but no gender differences in reported leisure time physical activity and in sleeping less than six hours a day. We have also shown that among female manual workers, family demands are consistently associated with different ill health indicators and health related behaviours, but there is almost no association with female nonmanual worker's or with male's health and health related behaviours. A significant finding was that, in contrast with the expected, living with people older than 65 years had a negative association with some health indicators among female manual workers.

Although we do not know the level of involvement in domestic work among the studied population, in a survey carried out in 1995 in the metropolitan area of Barcelona (Barcelona is the capital of Catalonia), even among women in the workforce, the majority of household tasks continued to be performed by them, ${ }^{46}$ with more or less resources depending on social class. The work overload, the conflicting demands of paid and unpaid work and the lack of time for themselves, may be some of the factors associated to manual class women's ill health.

When gender differences in health are analysed both the paid and the non-paid work should be considered, as well as the interaction between these two dimensions, gender and social class. Moreover more effort should be devoted to the consideration of the conditions and the psychosocial context of both paid and domestic work for both men and women. ${ }^{10}$ Many women in Europe choose to work part time when their domestic workload is high. However, part time work has been associated with a higher frequency of negative work characteristics than full time paid work. ${ }^{47}$ That suggests that part time work does not necessarily provide women with a solution when they attempt to balance work life and home life roles. In Catalonia, as probably in Spain and in other countries, private changes such as sharing domestic responsibilities, as well as active public policies for facilitating family care, taking into account the limitation of resources among women of lower social classes, are needed in order to reduce gender health inequalities attributable to the unequal distribution of family demands. 
POLICY IMPLICATIONS

- As women find it difficult to reconcile their job with their family responsibilities, the increased women's participation in the labour market puts a heavy strain on their health, placing on them the burden of neglected welfare policies. In Spain, a higher provision of publicly funded day care services for children under 3 years, after school facilities and services of home assistance as well as more family benefits are needed.

- In Spain, national and regional governments should explicitly promote universal family policies that integrate currently fragmented interventions on women, youth, elderly, labour or housing. Its implementation should be guaranteed at the local level and supplementary resources should be provided for families of more deprived social classes.

- Both at the national and regional level, there is a need to create commissions integrated by unions, employers, and public administrations such as the Ministry of Labour that guarantee gender equal opportunities at the workplace. Those policies should facilitate the conciliation of family and job demands by promoting the flexibility of working hours and non-discriminatory actions to motherhood.

- In the short-term, increasing part time work can help women to reconcile job and family demands. However, this approach has serious potential negative side effects such as worse working conditions, less opportunities for career development and a lower participation in the public domain and consequently women's interests ignored in general policies.

- Gender sensitive education activities in schools, workplace and mass media to increase the consciousness of sharing domestic roles and responsibilities should be increased. Moreover, there is a need to promote positive cultural attitudes towards the right to get public and affordable high quality care services.

L Artazcoz

C Borrell

Institut Municipal de Salut Pública, Barcelona

J Benach

Universitat Pompeu Fabra

C Valls-Llobet

Centre d'Anàlisi i Programes Sanitaris (CAPS)

1 Haavio-Manila E. Inequalities in health and gender. Soc Sci Med 1986;22:141-9.

2 Kandrack MA, Grant KR. Segall A. Gender differences in health related behaviour: some unanswered questions. Soc Sci Med 1991;32:579-90.

3 Hraba J, Lorenz F, Lee G, et al. Gender differences in health: evidence from the Czech Republic. Soc Sci Med 1996;43:1443-51.

4 Macintyre S, Hunt K, Sweeting H. Gender differences in health. Are things really as simple as they seem? Soc Sci Med 1996;42: 617-24.

5 Lahelma E, Arber S. Health inequalities among men and women in contrasting welfare states. Britain and three Nordic countries compared. Eur F Public Health 1994;4:21326.
6 Arber S, Lahelma E. Inequalities in women's and men's ill health: Britain and Finland compared. Soc Sci Med 1993;37:1055-68.

7 Popay J, Bartley M, Owen C. Gender inequalities in health: social position, affective disorders and minor morbidity. Soc Sci Med 1993;36:21-32.

8 Sorensen G, Verbrugge LM. Women, work, and health. Annu Rev Public Health 1987;8:235-51.

9 Hall EM. Double exposure: The combined impact of the home and work environments on psychosomatic strain in Swedish men and women. Int F Health Serv 1992;22:23960.

10 Hunt K, Annandale E. Just the job? Is the relationship between health and domestic and paid work gender

Bartley M, Popay J, Plewis I. Domestic conditions, paid employment and women's experience of ill-health. Sociology of Health and Illness 1992;14:313-43.

12 Bartley M. Measuring women's social position: the importance of theory. F Epidemiol Community Health 1999; 53:601-2.

13 Regidor E, Dominguez V, Navarro P, et al. The magnitude of differences in perceived general health associated with educational level in the regions of Spain. F Epidemiol Community Health 1999;53:288-93.

14 Borrell C, Plasencia A, Pasarin I, et al. Widening social inequalities in mortality: the case of Barcelona, a southern 67 .

15 Navarro V, Benach J. y la Comisión científica de estudios de las desigualdades sociales en salud en España. Desigualdades sociales en salud en España. Madrid: Ministerio de lic Health, The Johns Hopkins University, 1996.

16 Rohlfs I. Diferencias y desigualdades. La salud de hombres y mujeres en la ciudad de Barcelona. [MD Thesis.] Barcelona: mujeres en la ciudad de Barcelona. [MD Thesis.
Universitat Autònoma de Barcelona, 1998.

17 Fernandez E, Schiaffino A, Rajmil L, et al. Gender inequalities in health and health care services use in Cataloni (Spain). F Epidemiol Community Health 1999;53:218-22.

18 Subdirección General de Proceso de Datos del Ministerio de Trabajo y Asuntos Sociales. Anuario de Estadísticas Laborales y Sociales 1998. Madrid: Ministerio de Trabajo y Asuntos Sociales, 1999.

19 Ramos Torres R. Cronos dividido. Uso del tiempo y desigualdad entre hombres y mujeres en España. Bilbao: DIDOD, SA, 1990.

20 Servei Català de la Salut. Document Tècnic Encuesta de Salud de Catalunya. Enquesta de Salut de Catalunya 1994. Barcelona: Servei Català de la Salut, Departament de Sanitat i Seguretat Social, Generalitat de Catalunya, 1995.

21 Segovia J, Bartlett RF, Edwards AC. An empirical analysis of the dimensions of health status measures. Soc Sci Med the dimensions

22 Idler EL, Benyamini Y. Self-rated health and mortality: a review of twenty-seven community studies. F Health Soc Behav 1997;38:21-37.

23 Goldberg D. The detection of psychiatric illness by questionnaire. London: Oxford University Press, 1972.

24 Banks MH, Clegg CW, Jackson PR, et al. The use of the General Health Questionnaire as an indicator of mental health in occupational studies. F Occup Health 1980;53: 187-94.

25 Domingo A, Marcos J. Propuesta de un indicador de la "clase social" basado en la ocupación. Gac Sanit 1989;3: $320-6$.

26 Hosmer DW, Lemeshow S. Applied logistic regression. New York: John Wiley, 1989.

27 Guillen $M$, Juncà $S$, Rue $M$, et al. Effect of the sample design in the analysis of surveys with a complex design. [In Spanish.] Application to the Catalan Health Interview Survey. 399-402.

28 Verbrugge LM. The twain meet: empirical explanations of sex differences in health and mortality. $\mathcal{F}$ Health Soc Behav 1989;30:282-304

29 Walters V, Denton R, French S, et al. Paid work, unpaid work and social support: a study of the health of male and female nurses. Soc Sci Med 1996;43:1627-36.

30 Ross CE, Bird CE. Sex stratifications and health lifestyle: Consequences for men's and women's perceived health. $\mathcal{F}$ Health Soc Behav 1994;35:161-78.

31 Emslie C, Hunt K, Macintyre S. Problematizing gender, work and health: the relationship between gender, occupational grade, working conditions and minor morbidity in full-time bank employees. Soc Sci Med 1999;48:33-48.

32 Bird CE, Fremont AM. Gender, time use, and health. $\mathcal{F}$ Health Soc Behav 1991;32: 114-29.

33 Denton M, Walters V. Gender differences in structural and behavioural determinants of health: an analysis of the social production of health. Soc Sci Med 1999;48:1221-35

34 Arber S. Class, paid employment and family roles: making sense of structural disadvantage, gender and health status. Soc Sci Med 1991;32:425-36.

35 Macintyre S, Hunt K. Socio-economic position, gender and health. How do they interact? Fournal of Health Psychology 1997;2:315-34.

36 Walters V. Stress, anxiety and depression: women's accounts of their health problems. Soc Sci Med 1993;36:393-402.

37 Ross CE, Mirowsky J, Goldsteen K. The impact of the family on health. The decade in review. fournal of Marriage and the Family 1990;52:1059-78.

38 Ross CE, Mirowsky J. Child care and emotional adjustment to wives' employment. $\mathcal{F}$ Health Soc Behav 1988; 29:12738 
39 Ruigómez A, Alonso J, Antó JM. Salud percibida y capacidad funcional de la población anciana no institucion-

40 Bartley M, Sacker A, Firth D, et al. Social position, social roles and women's health in England: changing relationships 1984-1993. Soc Sci Med 1999;48:99-115.

41 Generalitat de Catalunya. Institut d'Estadística de Catalunya [page visited: May/31/2000]. Available in: URL http://www.idescat.es

42 Finkelstein MM. Back pain and parenthood. Occup Environ Med 1995;52:51-3.

43 Pate RR, Pratt M, Blair SN, et al. physical activity and Public Health. A recommendation from the Centers for Disease Control and Prevention and the American College of Sports Medicine. FAMA 1995; 273:402-7.
44 Lennon MC, Rosenfield S. Women and mental health. The interaction of job and family conditions. F Health Soc Behav 1992;33:316-27.

45 Cleary PD, Mechanic D. Sex differences in psychological distress among married people. F Health Soc Behav 1983;24:111-21.

46 Nel.lo O, Recio A, Solsona M, et al. La transformació de la societat metropolitana. Enquesta de la Regió Metropolitana de Barcelona. Condicions de vida i hábits de la població. Barcelona: Institut d'Estudis Metropolitans de Barcelona, Barcel 1998 .

47 Matthews S, Hertzman C, Ostry A, et al. Gender, work roles and psychosocial work characteristics as determinants of health. Soc Sci Med 1998;46:1417-24.

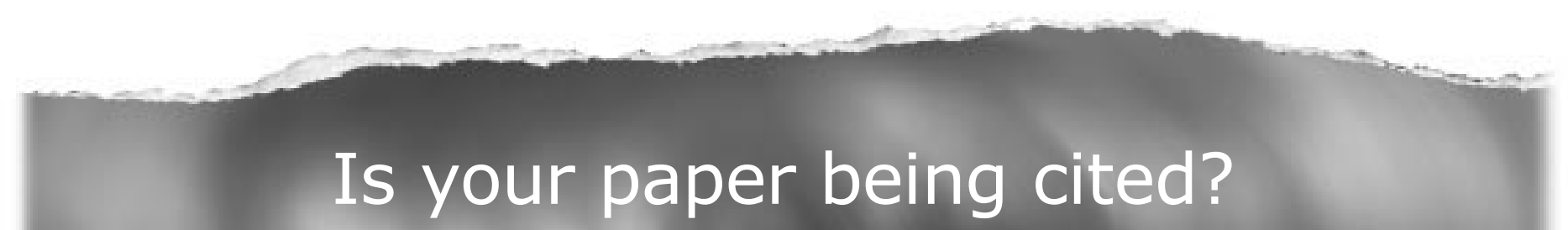

\section{CiteTrack service}

CiteTrack will alert you by email whenever new content in the Journal of Epidemiology and Community Health or a participating journal is published that matches criteria you want to track

Topics: Tell CiteTrack which words or subjects to watch for in new content Authors: Be alerted whenever key authors you are following publish a new paper Articles: Know whenever a paper of interest to you is referenced by another paper

\section{www.jech.com}

